\title{
Long-term bladeless LASIK outcomes with the FS200 Femtosecond and EX500 Excimer Laser workstation: the Refractive Suite
}

This article was published in the following Dove Press journal:

Clinical Ophthalmology

7 February 2013

Number of times this article has been viewed

\section{A John Kanellopoulos ${ }^{1,2}$ George Asimellis' \\ 'Laservision.gr Institute, Athens, Greece; ${ }^{2} \mathrm{NYU}$ Medical School, NY, USA}

Video abstract

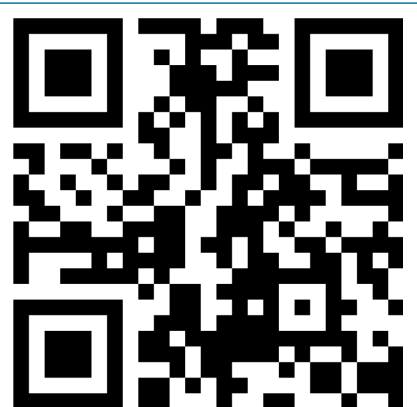

Point your SmartPhone at the code above. If you have a QR code reader the video abstract will appear. Or use: http://dvpr.es/WZ5C8

Correspondence: A John Kanellopoulos Laservision.gr Eye Institute, 17 Tsocha Street, Athens, Greece, II52 I

Tel +30 2I 07472777

Fax +30 2I 07472789

Email ajk@brilliantvision.com
Purpose: The evaluation of the safety, efficacy, and long-term stability of LASIK procedures utilizing novel platform comprising a femtosecond and excimer laser and multiple networked diagnostics.

Setting: Private clinical ophthalmology practice.

Patients and methods: In consecutive cases of myopic LASIK procedure with a novel refractive platform (FS200 Femtosecond and EX500 Excimer Laser), 190 eyes (from 109 different patients) were evaluated pre- and postoperatively for the following parameters: refractive error, best corrected distance visual acuity, uncorrected distance visual acuity, topography (Placidodisc based) and tomography (Scheimpflug-image based), wavefront analysis, pupillometry, and contrast sensitivity. Follow-up visits were conducted for at least 12 months.

Results: The change from pre- to postoperative mean refractive error was from $-5.29 \pm 2.39$ diopters (D) (range -8.0 to $-0.50 \mathrm{D}$ ) to $-0.27 \pm 0.09 \mathrm{D}$ at the 3 -month visit, $-0.27 \pm 0.10 \mathrm{D}$ at the 6 -month visit, and $-0.39 \pm 0.08 \mathrm{D}$ at the 1 -year visit. The change from pre- to postoperative refractive astigmatism was $-1.07 \pm 0.91 \mathrm{D}$ (range -4.25 to $0 \mathrm{D}$ ) to $-0.14 \pm 0.04 \mathrm{D}$ at 3 months, $-0.15 \pm 0.04$ at 6 months, and $-0.16 \pm 0.04$ at the 1 -year visit. The proportion of the eyes with postoperative astigmatism within $0.5 \mathrm{D}$ ranged between $95.6 \%$ and $99 \%$. The proportion of eyes achieving uncorrected distance visual acuity of 1.0 (decimal) was $93.0 \%$.

Conclusion: The myopic LASIK clinical results with the FS200 Femtosecond Laser and EX500 Excimer Laser showed outstanding efficacy, great safety, and long-term stability.

Keywords: bladeless LASIK flap, femtosecond laser, myopic correction, long-term stability, regression, astigmatism correction, post-LASIK refraction

\section{Introduction}

Laser-assisted in situ keratomileusis (LASIK) is a widely accepted method for correcting the refractive error, ${ }^{1,2}$ as evidenced by the long number of publications in the peer-reviewed literature.

In recent years, the use of bladeless LASIK surgery utilizing a femtosecond laser (named for its ultrashort pulses, with duration of few femtoseconds or quadrillionths of a second) for lamellar flap creation, as an alternative option to the mechanical microkeratome, ${ }^{3,4}$ has been studied as well.

A second laser involved in the procedure, the excimer provides the ablation and has also evolved significantly over the course of the past 10 years. Contemporary generation excimer lasers for refractive surgery operate with high pulse repetition (more than $400 \mathrm{~Hz})^{5,6}$ and scanning $\operatorname{spot}^{7}$ and can provide customized ablation, including aspheric ablation profiles, ${ }^{8}$ wavefront-guided, ${ }^{9,10}$ or topography-guided ${ }^{11,12}$ treatments. 
These improvements have further advanced the clinical outcomes of the LASIK procedure ${ }^{1,13}$ in correcting not just the spherocylindrical refractive error, but also the higher-order aberrations, by reducing the induced spherical aberration following myopic ablation. , $^{5,15}$

The purpose of this study was to evaluate the safety, efficacy, and long-term stability of myopic and myopic astigmatism corrective LASIK procedures utilizing the WaveLight ${ }^{\circledR}$ FS200 femtosecond ${ }^{16}$ and EX500 excimer laser refractive surgery platform.

\section{Materials and methods}

This prospective interventional case series study received approval by the Ethics Committee of our Institution, adherent to the tenets of the Declaration of Helsinki. Informed consent was obtained from each subject at the time of the intervention. The study was conducted on patients in our clinical practice, during scheduled pre- and postoperative procedure visits.

The 109 consecutive patients enrolled in the study underwent uncomplicated primary bilateral LASIK performed by the same surgeon (AJK) using the same refractive surgery platform (WaveLight FS200 Femtosecond Laser and WaveLight EX500 Excimer Laser; Alcon Laboratories, Ft Worth, TX, USA), between September 2009 and September 2010.

Preoperative spherical equivalent (SE) was between 0.00 and -8.00 diopters (D), and up to $4.25 \mathrm{D}$ of cylinder refractive error.

Exclusion criteria for the LASIK operation were: systemic or ocular diseases, eyes with history of corneal dystrophy or herpetic eye disease, topographic evidence of keratoconus (as evidenced by Placido topography) or warpage from contact lenses, corneal scaring, glaucoma, severe dry eye, and collagen vascular diseases. The average flap thickness (planned $110 \mu \mathrm{m}$ ) was $107 \pm 5 \mu \mathrm{m}$. The average flap diameter (planned $8.00 \mathrm{~mm}$ ) was $7.95 \pm 0.05 \mathrm{~mm}$. Flap thickness was measured by subtracting the central cornea pachymetry, measured with the EX500 following flap creation, from the central cornea pachymetry, measured preoperatively with the WaveLight Oculyzer $^{\mathrm{TM}}$ II diagnostic device (Alcon Laboratories) (with integrated Scheimpflug topography camera) and the WaveLight OB820 biometer (Alcon Laboratories) that were both integrated within the platform. ${ }^{17}$

All eyes were evaluated preoperatively for best corrected distance visual acuity (CDVA) and postoperatively for uncorrected distance visual acuity (UDVA). Preoperative evaluations included wavefront analysis, pupillometry, and contrast sensitivity. Postoperative examination included manifest and dilated refraction, slit-lamp microscopy, tonometry, and keratometry, by means of corneal topography and tomography assessment.

Postoperative follow-up examinations were conducted at 1 week, 3 months, 6 months, and 1 year. Data processed in this study represent the 3-, 6-, and 12-month visits.

Data were loaded and processed using web-based refractive analysis software (IBRA Ophthalmic Outcome Analysis System; Zubisoft GmbH, Oberhasli, Switzerland). ${ }^{18}$

\section{Results}

Of the 190 eyes, 96 (50.5\%) were right eyes, while 94 (49.5\%) were left eyes; 86 (45.3\%) belonged to female patients, while $104(54.7 \%)$ belonged to male patients. Mean age at the time of the operation was $28.8 \pm 7.8$ years, range 17 to 52 .

As shown in Table 1, the preoperative UDVA was $0.04 \pm 0.17$ (decimal), range 0.001 to 0.8 .

The postoperative average refractive error was $-0.27 \pm 0.09 \mathrm{D}$, at 3 months, $-0.27 \pm 0.10 \mathrm{D}$ at 6 months, and $-0.39 \pm 0.08 \mathrm{D}$ at the 1 -year visit. This compares with the preoperative average refractive error of $-5.29 \pm 2.39 \mathrm{D}$ (range -8.00 to 0.50 ).

Postoperative refractive astigmatism was to $-0.14 \pm 0.04$ $\mathrm{D}$ at 3 months, $-0.15 \pm 0.04$ at 6 months, and $-0.16 \pm 0.04$ at the 1 -year visit. This compares with the preoperative refractive astigmatism of $-1.07 \pm 0.91 \mathrm{D}$ (range -4.25 to $0 \mathrm{D})$.

\section{UDVA outcome and stability}

The UDVA (monocular) outcome and stability at 3, 6, and 12 months (Figure 1) shows that $94.7 \%$ of the eyes had postoperative unaided visual acuity better than 1.0 (decimal) at month 3, and maintained this for 1 year. Figure 1 also depicts the preoperative best CDVA.

\section{Safety of CDVA}

As shown in Figure 2, the safety distance visual acuity graph, at the 3-month visit comparison of preoperative best CDVA and postoperative UDVA, indicates that $33.3 \%$ of the eyes

Table I Preoperative parameters

\begin{tabular}{lll}
\hline Preoperative parameters & & \\
UDVA mean/SD & $0.04 \pm 0.09$ & Decimal \\
UDVA range & 0.001 to 0.8 & \\
SE mean/SD & $-5.29 \pm 2.39$ & Units (D) \\
SE range & -8.00 to -0.50 & \\
Cyl mean/SD & $-1.07 \pm 0.91$ & \\
Cyl range & -4.25 to 0 & \\
\hline
\end{tabular}

Abbreviations: UDVA, uncorrected distance visual acuity; SD, standard deviation; $\mathrm{SE}$, spherical equivalent; Cyl, cylinder; D, diopter. 


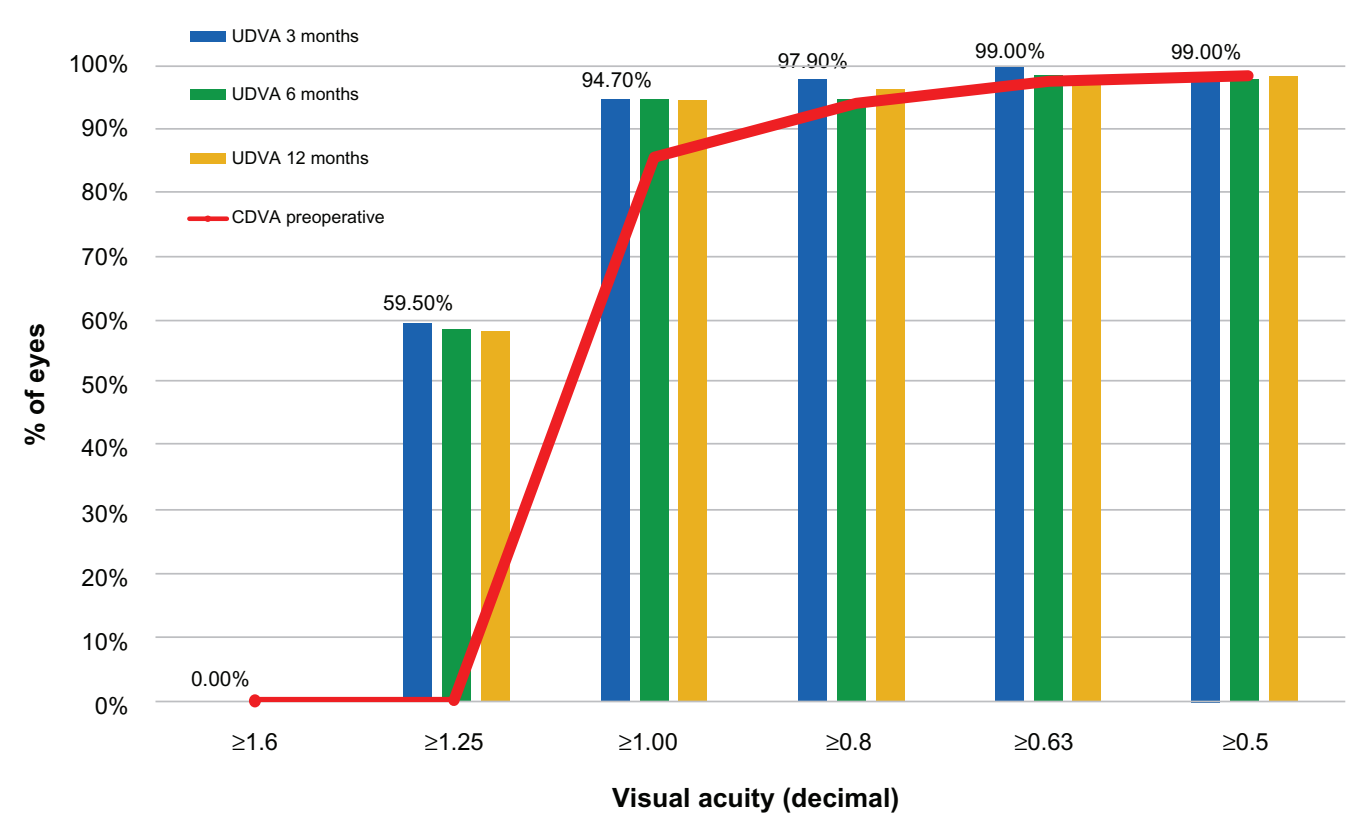

Figure I Postoperative uncorrected distance visual acuity at the 3-, 6-, and I2-month visits (clustered columns) versus preoperative best corrected visual acuity (stacked red line).

Abbreviations: UDVA, uncorrected distance visual acuity; CDVA, best corrected visual acuity.

were unchanged, while $59.2 \%$ of the eyes gained one Snellen line and $6.4 \%$ gained two or more Snellen lines. The proportion of eyes losing one line was less than $2 \%$, and so was the proportion of eyes losing two Snellen lines.

\section{Refractive stability and predictability}

The refractive stability is demonstrated by the SE correction, at the 12-month postoperative visit (Figure 3). Defocus equivalent results are presented in Figure 4.
Predictability is demonstrated in Figure 5, where the achieved SE versus attempted SE (in D) was plotted, for gate $=0.5 \mathrm{D}$. Of the 190 eyes shown, one eye $(0.5 \%)$ is marked with red, indicating overcorrection, $180(95 \%)$ are marked with green (indicating individual outcomes where the achieved spherical correction was within the gate, that is, $0.5 \mathrm{D}$ of the attempted correction), and nine eyes (5\%) are marked with blue, indicating undercorrection. The data have a linearity $\mathrm{a}=1.00$, with bias $\mathrm{b}=-0.16$, and the regres-

Gain/loss in Snellen lines

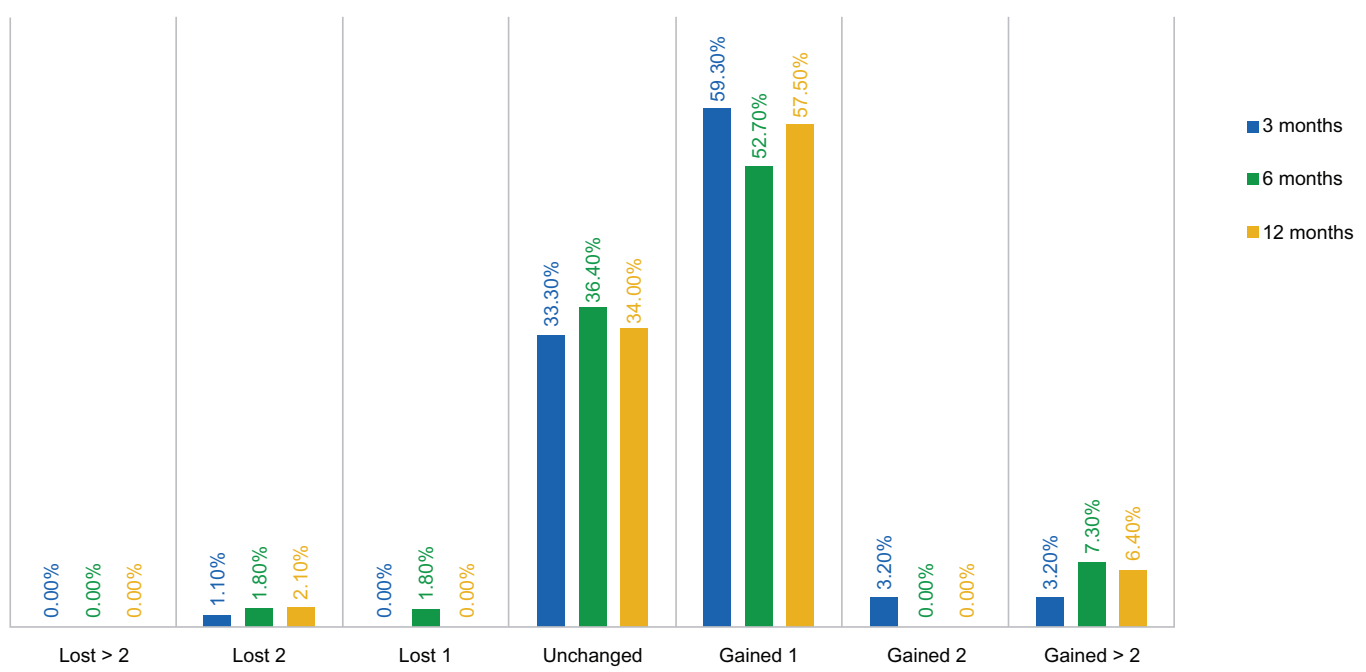

Figure 2 Safety distance visual acuity graph (\% of eyes with gain/loss in Snellen lines), at the 3-, 6-, and I2-month visits. 


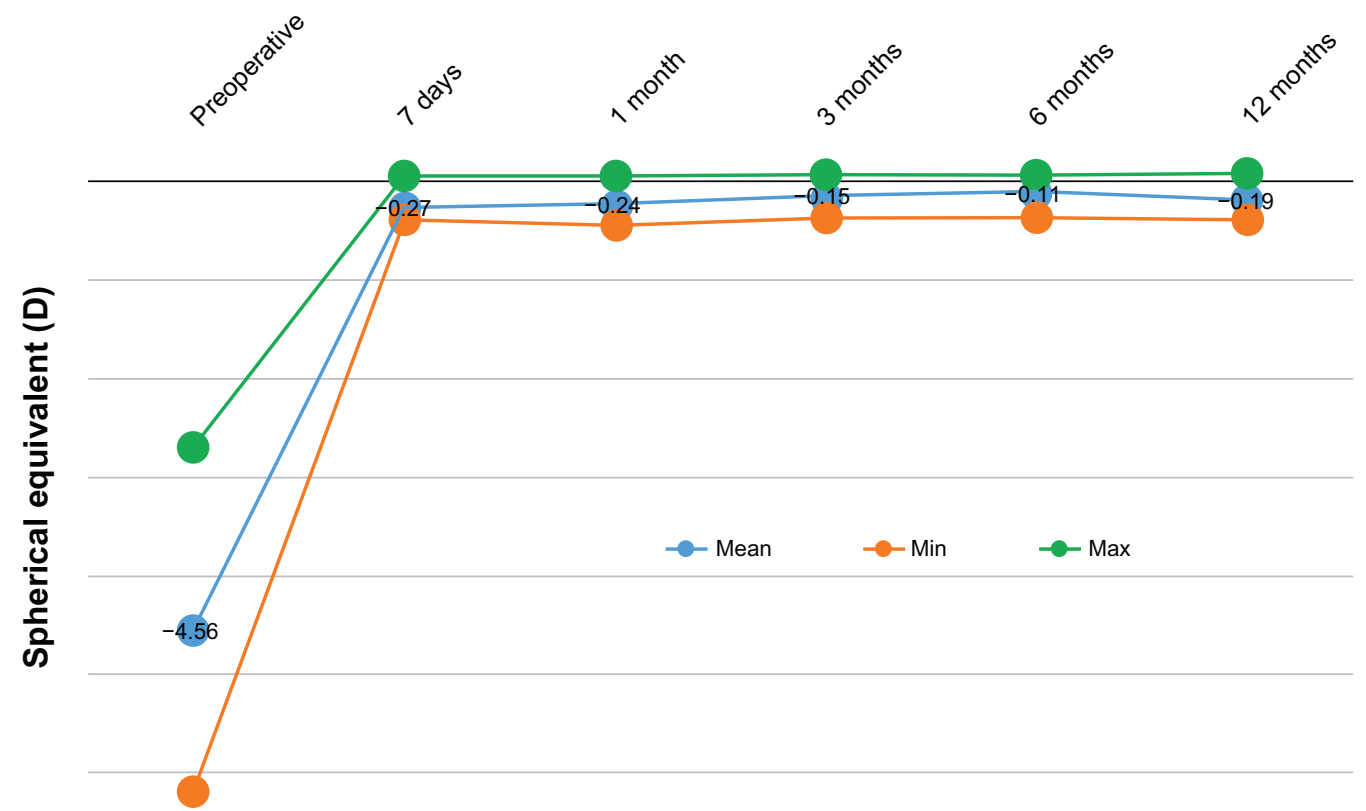

Figure 3 Stability of spherical equivalent for up to 12 months postoperatively. Abbreviation: D, diopter.

sion coefficient $(r)=0.98$. Likewise, in the 6-month followup visit, the linearity was $\mathrm{a}=1.02$, and for the 12 -month postoperatively follow-up visit, the linearity was a $=0.99$.

In a similar fashion, the SE refraction is depicted in Figure 6, where SE during the 3-month, 6-month, and 12-month postoperatively follow-up visits are shown.

\section{Keratometric and astigmatic changes and stability}

The comparison between postoperative and preoperative refractive astigmatism is demonstrated by the percentage of eyes within $0.25 \mathrm{D}$ of postoperative refractive astigmatism.
As shown in Figure 7, at the 3-month visit, $94.7 \%$ of the eyes showed astigmatism less than $0.25 \mathrm{D}$, at the 6-month visit, and $97.9 \%$ showed less than $0.5 \mathrm{D}$ refractive astigmatism at the 12-month visit.

Of interest is the comparison between postoperative and preoperative refractive astigmatism, in the form of a double angle-cylinder scatterplot of the surgically induced astigmatism minus the target-induced astigmatism, an example of which is shown in Figure 8.

The keratometric changes and stability is demonstrated by the K-flat and K-steep average values during the 1-, 3-, 6-, and 12-month postoperative visits (Figure 9).

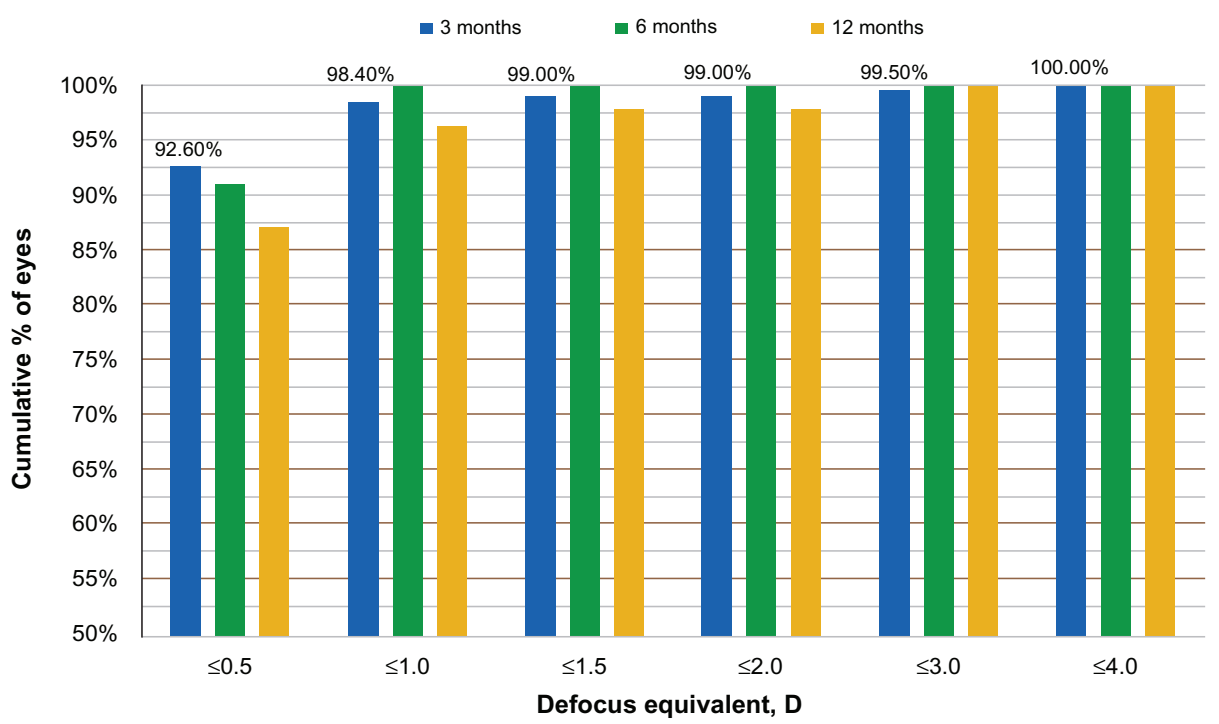

Figure 4 Defocus equivalent results at the 3-, 6-, and 12-month visits. Abbreviation: D, diopter. 


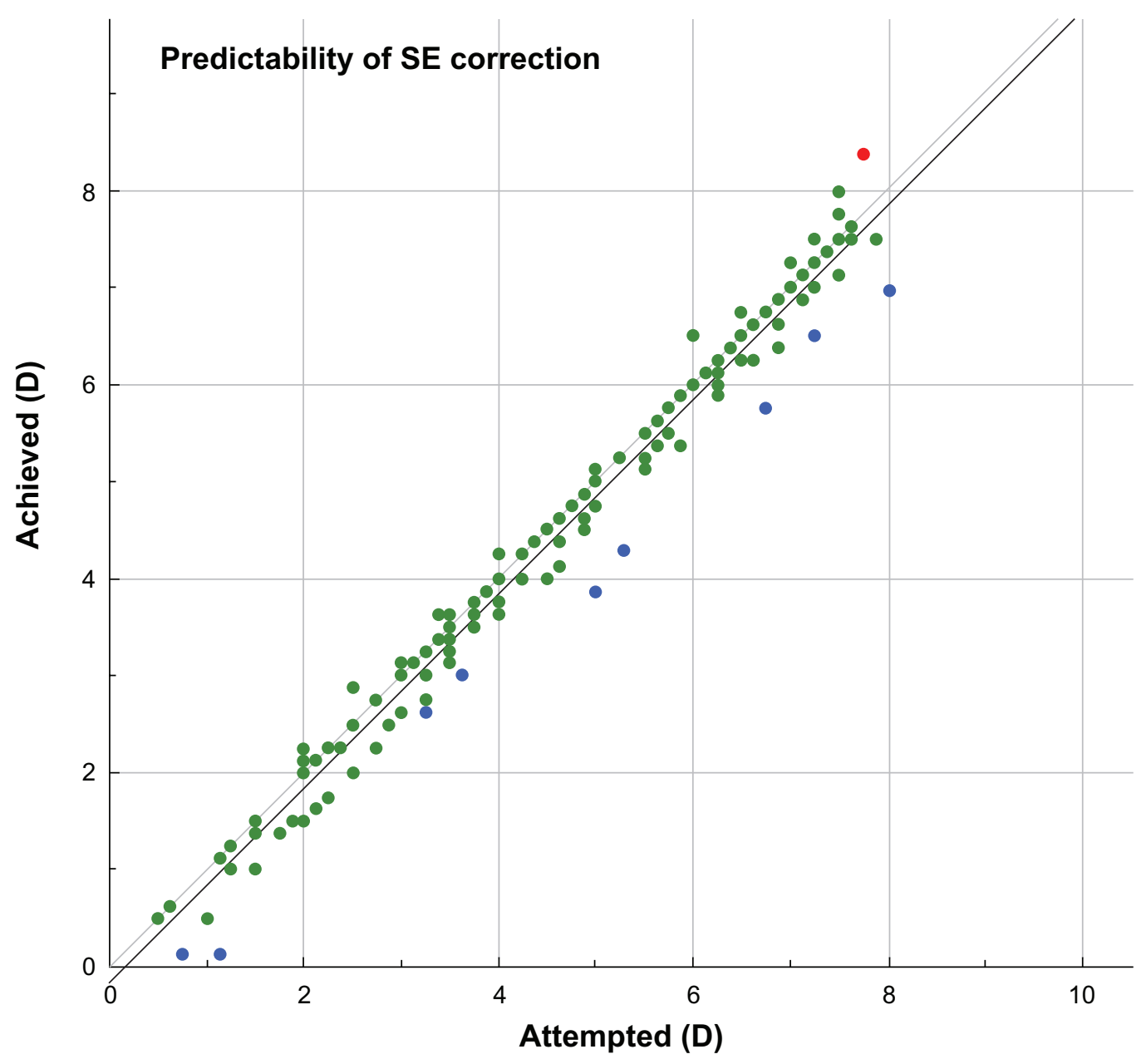

Figure 5 Predictability of spherical equivalent (SE) correction, showing achieved SE versus attempted SE. Abbreviation: D, diopter.

\section{Discussion}

In clinical practice, we used the combined WaveLight refractive surgery laser platform comprising the FS200 Femtosecond Laser, ${ }^{16}$ the EX500 Excimer Laser, and the series of networked diagnostic devices (including Vario Placido topography, Oculyzer II Scheimpflug topography imaging, a Tscherning wavefront system, and the OB820 biometer), that together constitute the Refractive Suite ${ }^{\circledR} .{ }^{17}$

Clinical results and features of the previous generations of the WaveLight excimer series $(200 \mathrm{~Hz}$ Allegretto and $400 \mathrm{~Hz}$ Eye Q) have been reported by our team. ${ }^{12,19}$

The EX500 laser, the latest evolution of the aforementioned excimer lasers, employs a $1050 \mathrm{~Hz}$ multidimensional active tracker (with estimated response time [latency] of 2 milliseconds and ability to track pupil size from 1.5 to $8 \mathrm{~mm}$ ), online optical pachymetry (enabling central cornea pachymetric measurements immediately following flap removal and during the LASIK procedure) to dynamically assess tissue removal, an onboard nitrogen generator (making the unit self-sufficient for nitrogen), and a $500 \mathrm{~Hz}$ laser pulse frequency that enables the treatment of each $\mathrm{D}$ of myopia in 1.4 seconds (based on a $6.0 \mathrm{~mm}$ optical zone of treatment). This enhanced speed may reduce stromal dehydration, flap shrinkage, sensitivity to eye movements, and patient fixation fatigue..$^{20}$

The flying spot in the excimer allows only one pulse in five to overlap and optimizes temporal and spatial shot distribution. Additional pulses are sent to the periphery to compensate for energy loss, reducing the potential for nighttime glare.

The Refractive Suite operates on its own Ethernet network and allows the import of diagnostic data from networked screening devices into the planning software tools of both lasers. For example, the Suite offers the ability to import the topometry data from the Oculyzer II into the laser treatment planning mode and to accordingly customize the excimer treatment to the cornea (for eg, topography-guided treatment). ${ }^{12}$

The long-term clinical results with the systems described above reported here show impressive refractive outcome, 


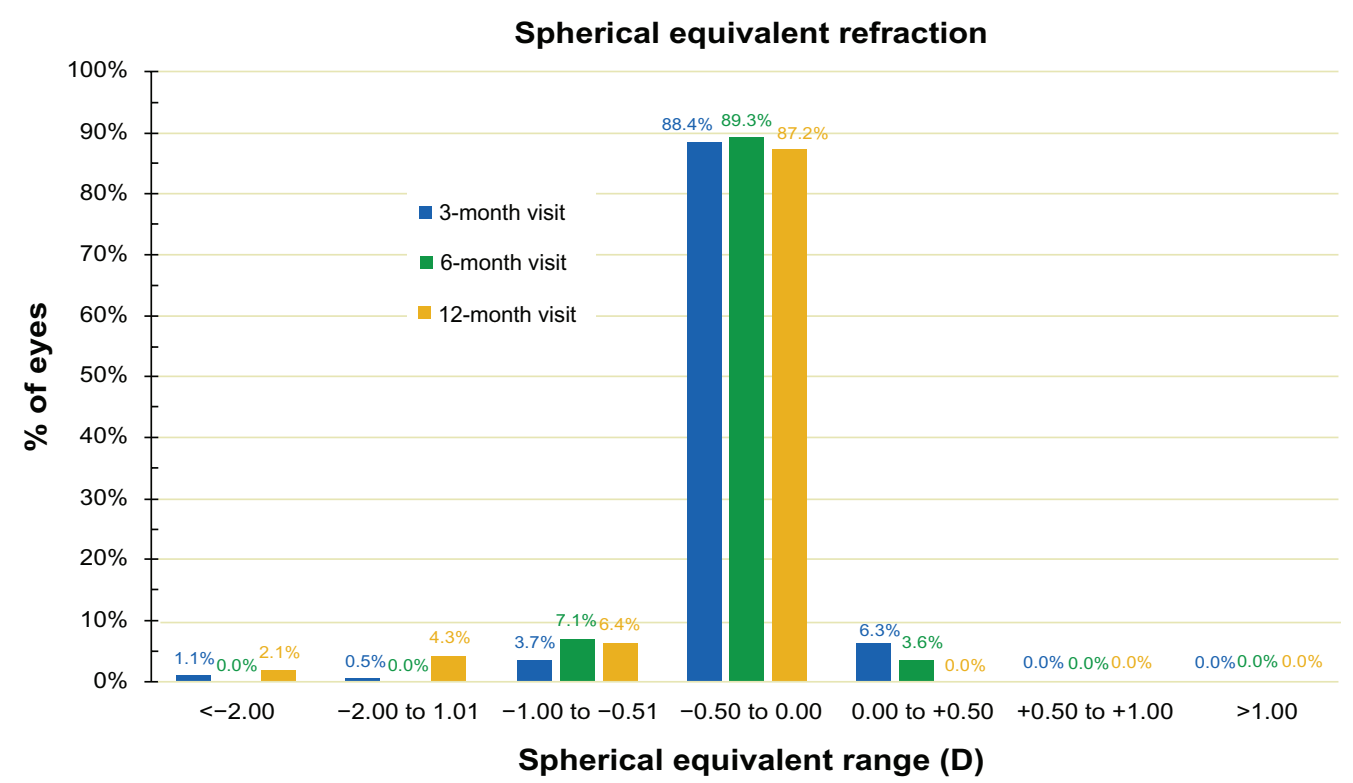

Figure 6 Spherical equivalent correction at the 3-, 6-, and I2-months postoperative visits. Percentage of eyes (\%) versus spherical equivalent range. Abbreviation: D, diopter.

predictability, and stability. The long-term clinical results with the systems described above reported in this study show impressive refractive outcome, predictability, and stability, such as the percentage of eyes achieving a postoperative spherical equivalent refraction within $0.5 \mathrm{D}$ of the target (that is, from $-0.50 \mathrm{D}$ to $+0.50 \mathrm{D}$ ) and the total range of postoperative refractive error, which are considered markers of the achieved quality of a refractive procedure. The excellent refractive results obtained in terms of SE refrac- tion, were also confirmed by the defocus equivalent results. The defocus equivalent results show that $92.6 \%$ of the eyes are within $-0.5 \mathrm{D}$ and $+0.5 \mathrm{D}$, a result achieved at the first three months. This parameter gives a better understanding of the accuracy of a procedure for correcting the entire refractive error.

In terms of visual acuity (Figure 1), $94.7 \%$ of the eyes had UDVA larger or equal to 1.00 (decimal). Before surgery, only $85.5 \%$ had best CDVA of 1.0 (with their best prescription

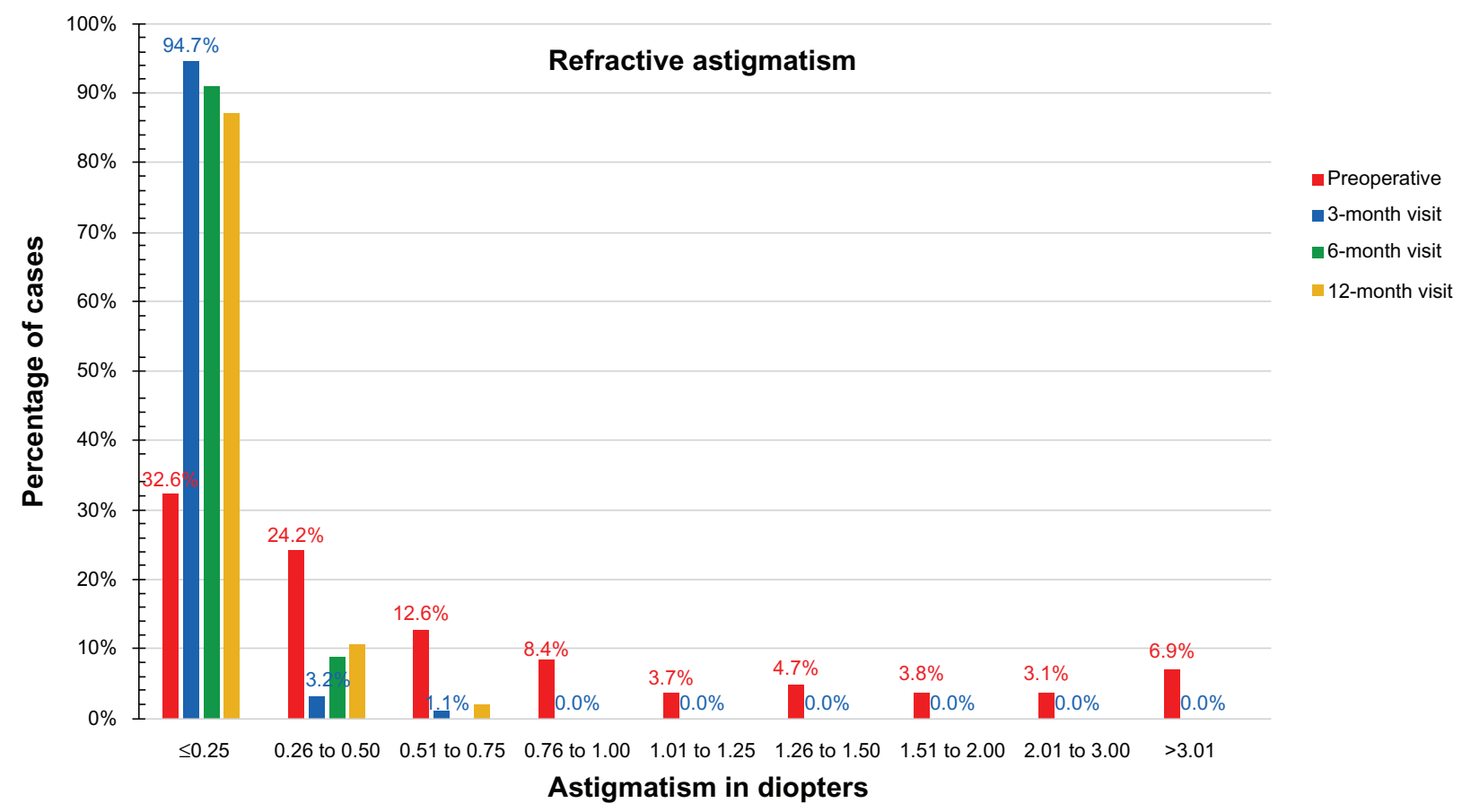

Figure 7 Refractive astigmatism, preoperatively and at the 3-, 6-, and 12-month postoperative visits. Percentage of eyes versus refractive astigmatism (measured in diopters [D]). 


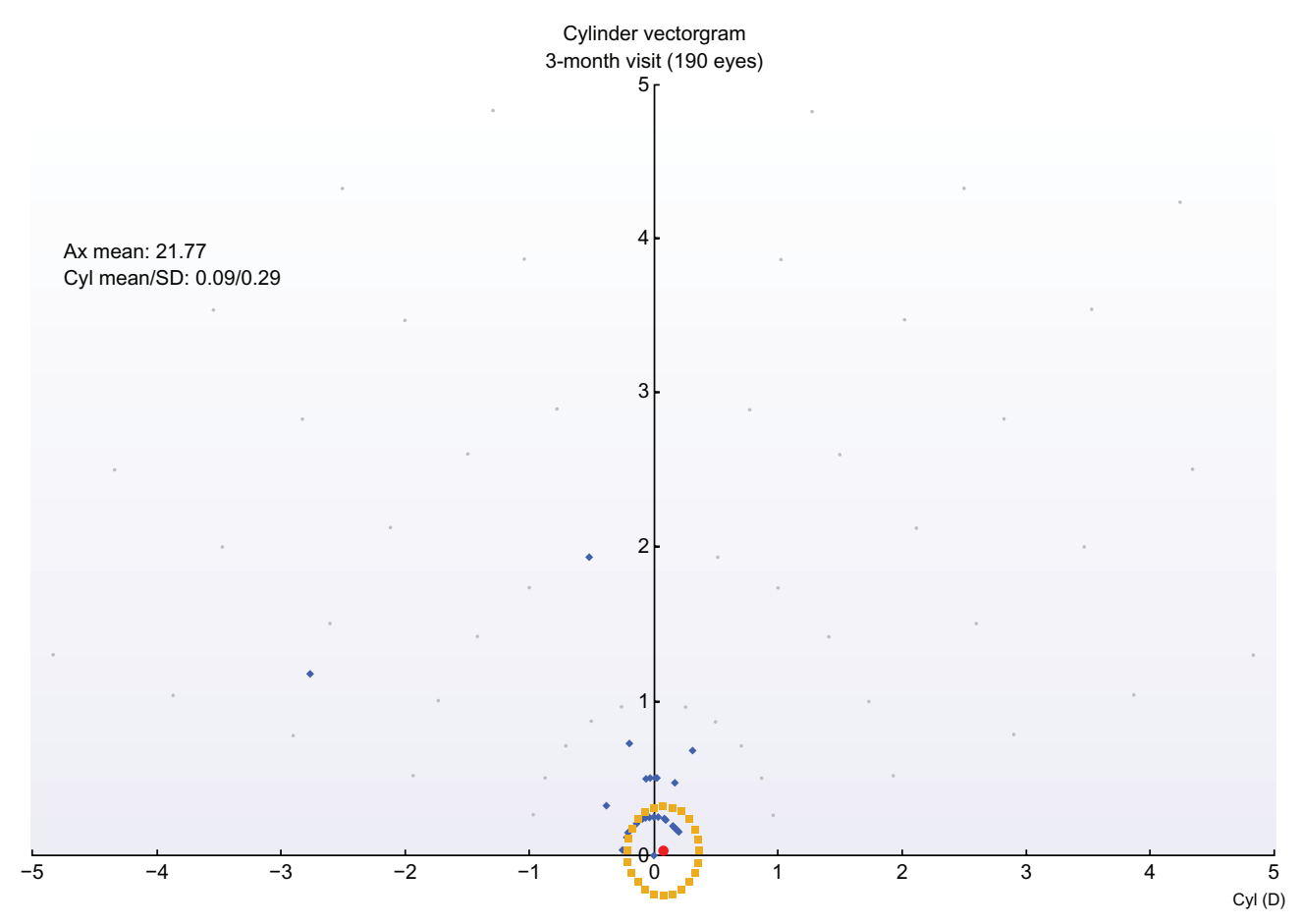

Figure 8 Double-angle cylinder scatterplot of surgically induced astigmatism minus target induced astigmatism (3-month postop visit). Abbreviations: Ax, axis; Cyl, cylinder; D, diopter; SD, standard deviation.

spectacles or contact lenses). A significant percentage (59.5\%) of eyes were found to have UDVA better or equal to 1.25 (decimal).

In terms of gain/loss in Snellen lines - again, comparing uncorrected (UDVA) and best corrected (CDVA) - only $2.1 \%$ (four eyes) of the 190 had a loss in Snellen lines, while the majority $(63.90 \%)$ gained at least one line. These visual outcomes are very satisfactory.
The predictability of the outcome was extremely accurate. As shown in Figure 5, of the 190 eyes shown, one eye (0.5\%) was marked with red, indicating overcorrection, 180 (95\%) were marked with green, within $0.5 \mathrm{D}$, and nine $(5 \%)$ were marked with blue, indicating undercorrection.

The stability of the outcome is evidenced by the stability of the SE over the course of 12 months, as shown in

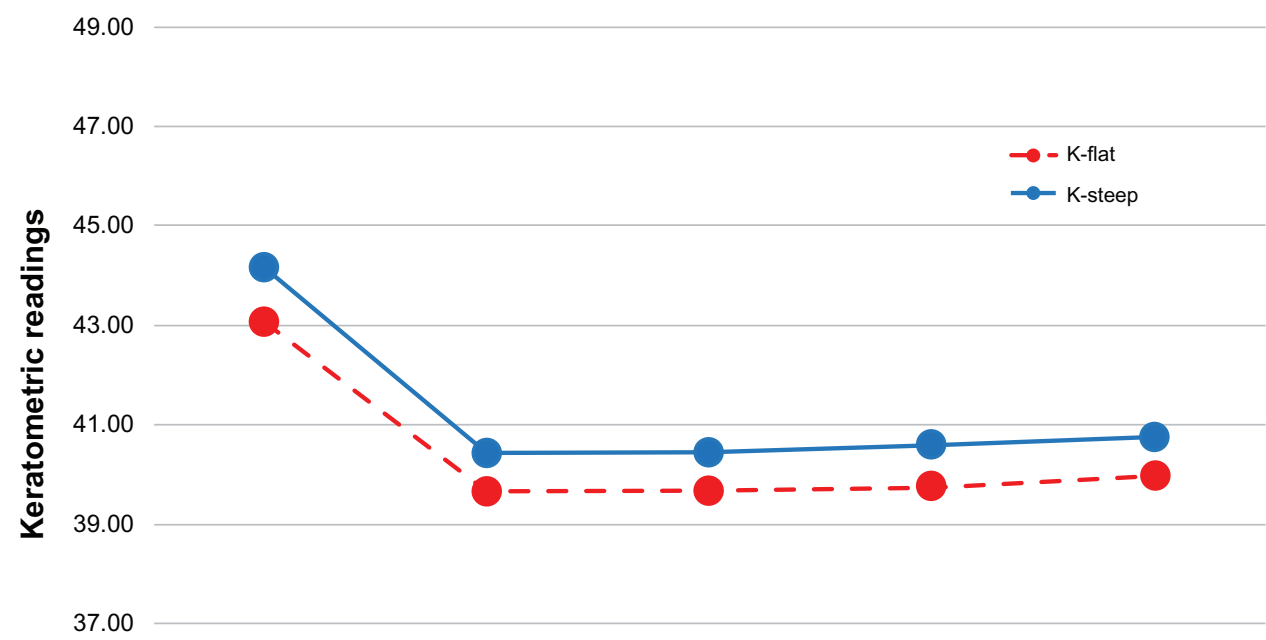

\begin{tabular}{|c|c|c|c|c|c|}
\multicolumn{1}{c|}{35.00} & Preoperative & 1-month visit & 3-month visit & 6-month visit & 12-month visit \\
\cline { 2 - 6 } & 43.06 & 39.64 & 39.67 & 39.73 & 39.94 \\
\hline$\rightarrow-$ K-flat & 44.15 & 40.4 & 40.44 & 40.58 & 40.72 \\
\hline
\end{tabular}

Figure 9 Keratometric readings for up to 12 months of follow-up. Abbreviation: D, diopter. 
Figures 3 and 6 . The proportions of eyes achieving postoperative manifest refraction $\mathrm{SE}$ in the -0.50 to $0.00 \mathrm{D}$ range was more than $87 \%$ at the 12 -month visit (Figure 6); 95.7\% were within $\pm 1.0 \mathrm{D}$ at the 1-year results. These results compare very favorably to other studies, ${ }^{21}$ in which for the same range of $\pm 1.0 \mathrm{D}$, the proportions were in the range of $98 \%$.

More importantly, $0 \%$ cases had hyperopic regression up to $+0.5 \mathrm{D}$, at the 1-year follow-up visit.

The slight positive slope in the keratometric readings (similar for both the flat and the steep meridian) might be an indication of mild progressive corneal steepening. In Figure 9 we observe $\mathrm{a}+0.1 \mathrm{D}$ of keratometric power increase over the course of 1 year. This is an indication that corneal stiffening might be required for all LASIK cases, in the form of cross linking applied at the corneal stroma prior to repositioning of the flap. ${ }^{22}$ This procedure, known as LASIK-extra, is under investigation by our team. ${ }^{23}$

The vector analysis of cylinder showed overall satisfactory results with a relatively good index of success. The analysis of surgically induced astigmatism and target-induced astigmatism disclosed the presence of some systematic induced cylinder (Figure 7), with a constant trend toward the $90^{\circ}$ axis. This may be related to the position of the hinge (always nasal) or it may be due to the hinge protection software. Regarding the cylinder correction (Figure 7), in 98\% of the eyes, after 1 year, the residual cylinder power was less than $0.5 \mathrm{D}$, compared with $67.4 \%$ of the eyes that preoperatively had cylinder power more than $0.25 \mathrm{D}$ and up to $6.00 \mathrm{D}$.

\section{Conclusion}

The long-term clinical results with the Alcon/WaveLight Refractive Suite show impressive refractive outcome, predictability, and stability. Safety, efficacy, and long term stability are also remarkable. The networking of diagnostic devices increases ease and safety when both the femtosecond and the excimer lasers are used.

\section{Disclosure}

AJK is a consultant for Alcon laboratories. GA has no financial conflicts to report.

\section{References}

1. Kugler LJ, Wang MX. Lasers in refractive surgery: history, present, and future. Appl Opt. 2010;49(25):F1-F9.

2. Lukenda A, Martinović ZK, Kalauz M. Excimer laser correction of hyperopia, hyperopic and mixed astigmatism: past, present, and future. Acta Clin Croat. 2012;51(2):299-304.

3. Reggiani-Mello G, Krueger RR. Comparison of commercially available femtosecond lasers in refractive surgery. Expert Rev Opthalmol. 2011; 6(1):55-65.
4. Salomão MQ, Wilson SE. Femtosecond laser in laser in situ keratomileusis. J Cataract Refract Surg. 2010;36(6):1024-1032.

5. Vega-Estrada A, Alió JL, Arba Mosquera S, Moreno LJ. Corneal higher order aberrations after LASIK for high myopia with a fast repetition rate excimer laser, optimized ablation profile, and femtosecond laserassisted flap. J Refract Surg. 2012;28(10):689-696.

6. Winkler von Mohrenfels C, Khoramnia R, Lohmann CP. Comparison of different excimer laser ablation frequencies $(50,200$, and $500 \mathrm{~Hz})$. Graefes Arch Clin Exp Ophthalmol. 2009;247(11):1539-1545.

7. Iseli HP, Mrochen M, Hafezi F, Seller T. Clinical photoablation with a 500-Hz scanning spot excimer laser. J Refract Surg. 2004;20(6): 831-834.

8. de Ortueta D, Magnago T, Triefenbach N, Arba Mosquera S, Sauer U, Brunsmann U. In vivo measurements of thermal load during ablation in high-speed laser corneal refractive surgery. J Refract Surg. 2012;28(1): $53-58$.

9. Aslanides IM, Kolli S, Padron S, Arba Mosquera S. Stability of therapeutic retreatment of corneal wavefront customized ablation with the SCHWIND CAM: 4-year data. J Refract Surg. 2012;28(5):347-352.

10. Smadja D, Reggiani-Mello G, Santhiago MR, Krueger RR. Wavefront ablation profiles in refractive surgery: description, results, and limitations. J Refract Surg. 2012;28(3):224-232.

11. Kanellopoulos AJ. Topography-guided custom retreatments in 27 symptomatic eyes. J Refract Surg. 2005;21(5):S513-S518.

12. Kanellopoulos AJ. Topography-guided hyperopic and hyperopic astigmatism femtosecond laser-assisted LASIK: long-term experience with the $400 \mathrm{~Hz}$ eye-Q excimer platform. Clin Ophthalmol. 2012;6: 895-901.

13. Zheng H, Song LW. Visual quality of Q-value-guided LASIK in the treatment of high myopia. Yan Ke Xue Bao. 2011;26(4):208-210.

14. Alio JL, Vega-Estrada A, Piñero DP. Laser-assisted in situ keratomileusis in high levels of myopia with the amaris excimer laser using optimized aspherical profiles. Am J Ophthalmol. 2011;152(6):954-963.

15. El Awady HE, Ghanem AA, Saleh SM. Wavefront-optimized ablation versus topography-guided customized ablation in myopic LASIK: comparative study of higher order aberrations. Ophthalmic Surg Lasers Imaging. 2011;42(4):314-320.

16. Mrochen M, Wüllner C, Krause J, Klafke M, Donitzky C, Seiler T. Technical aspects of the WaveLight FS200 femtosecond laser. J Refract Surg. 2010;26(10):S833-S840.

17. Kanellopoulos AJ, Asimellis G. Correlation between central corneal thickness, anterior chamber depth, and corneal keratometry as measured by Oculyzer II and WaveLight OB820 in preoperative cataract surgery patients. J Refract Surg. 2012;28(12):895-900.

18. Zuberbühler B, Galloway P, Reddy A, Saldana M, Gale R. A web-based information system for management and analysis of patient data after refractive eye surgery. Comput Methods Programs Biomed. 2007;88(3): 210-216.

19. Kanellopoulos AJ. Long term results of a prospective randomized bilateral eye comparison trial of higher fluence, shorter duration ultraviolet A radiation, and riboflavin collagen cross linking for progressive keratoconus. Clin Ophthalmol. 2012;6:97-101.

20. Matsuura T, Ikeda H, Idota N, Motokawa R, Hara Y, Annaka M. Anisotropic swelling behavior of the cornea. J Phys Chem B. 2009; 113(51):16314-16322.

21. Han DC, Chen J, Htoon HM, Tan DT, Mehta JS. Comparison of outcomes of conventional WaveLight $\left({ }^{\circledR}\right)$ Allegretto Wave $\left({ }^{\circledR}\right)$ and Technolas $\left({ }^{\circledR}\right)$ excimer lasers in myopic laser in situ keratomileusis. Clin Ophthalmol. 2012;6:1159-1168.

22. Celik HU, Alagöz N, Yildirim Y, et al. Accelerated corneal crosslinking concurrent with laser in situ keratomileusis. J Cataract Refract Surg. 2012;38(8):1424-1431.

23. Kanellopoulos AJ. Long-term safety and efficacy follow-up of prophylactic higher fluence collagen cross-linking in high myopic laserassisted in situ keratomileusis. Clin Ophthalmol. 2012;6:1125-1130. 
Clinical Ophthalmology

\section{Publish your work in this journal}

Clinical Ophthalmology is an international, peer-reviewed journal covering all subspecialties within ophthalmology. Key topics include: Optometry; Visual science; Pharmacology and drug therapy in eye diseases; Basic Sciences; Primary and Secondary eye care; Patien Safety and Quality of Care Improvements. This journal is indexed on

PubMed Central and CAS, and is the official journal of The Society of Clinical Ophthalmology (SCO). The manuscript management system is completely online and includes a very quick and fair peer-review system, which is all easy to use. Visit http://www.dovepress.com/ testimonials.php to read real quotes from published authors. 